\title{
Attitudes toward genomic tumor profiling tests in Japan: patients, family members, and the public
}

\author{
Akiko Nagai ${ }^{1} \cdot$ Izen $\mathrm{Ri} \mathbb{D}^{2,3} \cdot$ Kaori Muto ${ }^{1}$ \\ Received: 23 October 2018 / Revised: 14 December 2018 / Accepted: 14 December 2018 / Published online: 10 January 2019 \\ (c) The Author(s) 2019. This article is published with open access
}

\begin{abstract}
Genomic tumor profiling tests (GTPTs) to find molecular targeted drugs for patients with advanced cancer are being introduced into clinical settings, which may result in secondary germline findings. Although small-scale qualitative studies have revealed patients' attitudes toward GTPTs and preferences on receiving germline findings, no large-scale quantitative research exists that includes family members. We conducted anonymous surveys with 757 cancer patients (CPs), 763 family members (FMs), and 3697 general adults (GAs) in Japan. Awareness of GTPTs was low in all groups, however, both CPs and FMs showed a higher degree of recognition in the benefits of GTPTs. FMs wanted information on germline findings to be shared more than the CPs. Since advanced CPs may have psychological burdens that make it difficult to express their opinions on their therapeutic options and sharing germline findings, GTPTs should be offered with advanced care planning for patients.
\end{abstract}

Genomic tumor profiling tests (GTPTs) enable to identify tumor-specific genomic changes and find molecular targeted drugs for patients with advanced cancer [1]. Despite the low rate of clinical actionability [2-4], some GTPTs can simultaneously detect hundreds of oncogene, while others can add germline variants, like BRCA and TP53 mutations, within certain percentages. The American College of Medical Genetics regularly renews the list of genes to be returned for their actionable natures [5], since its first list prompted extensive debates on its ethical validity and utility [6-8]. Germline variants derived from GTPTs, which are recommended by the list, may be candidates to return to patients. Previous small-scale studies on patients with cancer, mostly conducted through semi-structured interviews,

Supplementary information The online version of this article (https:// doi.org/10.1038/s10038-018-0555-3) contains supplementary material, which is available to authorized users.

Kaori Muto

krmt@ims.u-tokyo.ac.jp

1 Department of Public Policy, The Institute of Medical Sciences, The University of Tokyo, Minato-ku, Tokyo, Japan

2 Graduate School of Interdisciplinary Information Studies, The University of Tokyo, Tokyo, Japan

3 Japan Society for the Promotion of Science, Tokyo, Japan found that patients welcomed GTPTs, and that some were also interested in knowing germline findings [9-12], despite limited comprehension of cancer genomics and the implications of tumor profiling [13]. This paper presents the results of a large-scale survey that aims to learn more about the attitudes toward GTPTs held by Japanese cancer patients, family members and the general public.

Cross-sectional anonymous online surveys were distributed to 2661 cancer patients (CPs) and family members of cancer patients (FMs) aged 20-79 in March 2018, and another 38,156 adults in the general Japanese population (GAs) aged 20-69 from May to June 2018. These two groups were extracted from a database of 1.5 million people compiled by INTAGE Inc. from national census data, or an INTAGE sub-panel on self-reported illnesses. CPs and FMs were registered to the sub-panel as people who were currently going to hospital for cancer or who were living with a person who had undergone cancer treatment within the last year. Before answering their questions, respondents were given a brief explanation on GTPTs, including their cost, the possibility that results would not provide useful information, the potential unavailability of the drugs identified by the results, the possibility of respondents being asked to provide test results and related data to public databases, and the possibility of finding germline variants.

The combined group of CPs and FMs included 1761 respondents (response rate: $66.2 \%$ ), while the GAs group 
Table. 1 Respondent characteristics and awareness of and attitudes toward GTPTs

\begin{tabular}{|c|c|c|c|c|c|c|c|c|c|c|c|c|}
\hline & \multicolumn{4}{|c|}{ CPs $(n=757)$} & \multicolumn{4}{|c|}{ FMs $(n=763)$} & \multicolumn{4}{|c|}{ GAs $(n=3697)$} \\
\hline & \multicolumn{2}{|c|}{ Males } & \multicolumn{2}{|c|}{ Females } & \multicolumn{2}{|c|}{ Males } & \multicolumn{2}{|c|}{ Females } & \multicolumn{2}{|l|}{ Males } & \multicolumn{2}{|c|}{ Females } \\
\hline & $n$ & $\%$ & $n$ & $\%$ & $n$ & $\%$ & $n$ & $\%$ & $n$ & $\%$ & $n$ & $\%$ \\
\hline Total & 258 & 34.1 & 499 & 65.9 & 353 & 46.3 & 410 & 53.7 & 2114 & 57.2 & 1583 & 42.8 \\
\hline \multicolumn{13}{|l|}{ Age group (years) } \\
\hline $20-29$ & 1 & 0.4 & 2 & 0.4 & 7 & 2.0 & 29 & 7.1 & 408 & 19.3 & 356 & 22.5 \\
\hline $30-39$ & 6 & 2.3 & 31 & 6.2 & 27 & 7.6 & 71 & 17.3 & 470 & 22.2 & 333 & 21.0 \\
\hline $40-49$ & 27 & 10.5 & 150 & 30.1 & 102 & 28.9 & 109 & 26.6 & 542 & 25.6 & 362 & 22.9 \\
\hline $50-59$ & 65 & 25.2 & 212 & 42.5 & 132 & 37.4 & 109 & 26.6 & 362 & 17.1 & 264 & 16.7 \\
\hline $60-69$ & 159 & 61.6 & 104 & 20.8 & 85 & 24.1 & 92 & 22.4 & 332 & 15.7 & 268 & 16.9 \\
\hline \multicolumn{13}{|l|}{ Marital status } \\
\hline Unmarried & 25 & 9.7 & 68 & 13.6 & 111 & 31.4 & 128 & 31.2 & 845 & 40.0 & 483 & 30.5 \\
\hline Married & 233 & 90.3 & 431 & 86.4 & 242 & 68.6 & 282 & 68.8 & 1269 & 60.0 & 1100 & 69.5 \\
\hline \multicolumn{13}{|l|}{ Do you have any children? } \\
\hline No & 64 & 24.8 & 175 & 35.1 & 163 & 46.2 & 191 & 46.6 & 1134 & 53.6 & 754 & 47.6 \\
\hline Yes & 194 & 75.2 & 324 & 64.9 & 190 & 53.8 & 219 & 53.4 & 980 & 46.4 & 829 & 52.4 \\
\hline \multicolumn{13}{|l|}{ Educational background } \\
\hline Junior high school & 5 & 1.9 & 11 & 2.2 & 7 & 2.0 & 9 & 2.2 & 63 & 3.0 & 53 & 3.3 \\
\hline High school & 63 & 24.4 & 143 & 28.7 & 91 & 25.8 & 129 & 31.5 & 629 & 29.8 & 523 & 33.0 \\
\hline Occupational school & 27 & 10.5 & 82 & 16.4 & 42 & 11.9 & 70 & 17.1 & 315 & 14.9 & 267 & 16.9 \\
\hline Junior college & 9 & 3.5 & 115 & 23.0 & 4 & 1.1 & 87 & 21.2 & 45 & 2.1 & 264 & 16.7 \\
\hline University or graduate school & 154 & 59.7 & 148 & 29.7 & 209 & 59.2 & 115 & 28.0 & 1062 & 50.2 & 476 & 30.1 \\
\hline \multicolumn{13}{|l|}{ Awareness of genetic testing } \\
\hline Familiar with its contents & 46 & 17.8 & 95 & 19.0 & 82 & 23.2 & 74 & 18.0 & 377 & 17.8 & 281 & 17.8 \\
\hline Have heard of it & 177 & 68.6 & 353 & 70.7 & 229 & 64.9 & 286 & 69.8 & 1163 & 55.0 & 880 & 55.6 \\
\hline Have never heard of it & 35 & 13.6 & 51 & 10.2 & 42 & 11.9 & 50 & 12.2 & 574 & 27.2 & 422 & 26.7 \\
\hline \multicolumn{13}{|l|}{ Awareness of GTPTs } \\
\hline Familiar with their contents & 8 & 3.1 & 5 & 1.0 & 13 & 3.7 & 6 & 1.5 & 36 & 1.7 & 18 & 1.1 \\
\hline Have heard of them & 58 & 22.5 & 121 & 24.2 & 91 & 25.8 & 95 & 23.2 & 386 & 18.3 & 262 & 16.6 \\
\hline Have never heard of them & 192 & 74.4 & 373 & 74.8 & 249 & 70.5 & 309 & 75.4 & 1692 & 80.0 & 1303 & 82.3 \\
\hline \multicolumn{13}{|l|}{ Willingness to undergo GTPTs } \\
\hline Want to undergo & 98 & 38.0 & 141 & 28.3 & 184 & 52.1 & 172 & 42.0 & 566 & 26.8 & 337 & 21.3 \\
\hline Don't want to undergo & 45 & 17.4 & 102 & 20.4 & 31 & 8.8 & 34 & 8.3 & 458 & 21.7 & 335 & 21.2 \\
\hline Cannot decide & 115 & 44.6 & 256 & 51.3 & 138 & 39.1 & 204 & 49.8 & 1090 & 51.6 & 911 & 57.5 \\
\hline
\end{tabular}

Abbreviation: $G T P T s$, genomic tumor profiling tests; $C P s$, cancer patients; $F M s$, family members of cancer patients; GAs, general adults included 10,739 respondents (response rate: $28.1 \%$ ). We excluded respondents aged $70+$ from the first group and classified them as people with a history of cancer (CPs, $n=757$ ), or people who had a history of cancer in their family (FMs, $n=763$ ). We extracted respondents who indicated that they had no personal or family history of cancer from the GAs group (GAs, $n=3697$ ). The mean age of CPs was 55.1 years (range: 28-69 years), while it was 50.3 years (range 20-69 years) for FMs and 43.2 years (range 20-69 years) for GAs. Regarding their awareness of GTPTs, $74.6 \%$ of CPs, $73.1 \%$ of FMs and $81.0 \%$ of GAs responded that they had "never heard" of them (Table 1).
In the evaluation of the benefits and concerns about GTPTs, $81.8 \%$ of FMs and $77.3 \%$ of CPs expected that cancer precision medicine would become popular. However, $74.0 \%$ of FMs and $73.2 \%$ of CPs expressed concerns about health disparities by income (Fig. 1). FMs highly valued the potential benefits of GTPTs; in fact, they were more likely than any other group to value the fact that GTPTs would help to diagnose and treat patients and family members. These trends were observed in the distribution stratified by sex and age (Supplemental Fig. 1). Remarkably high percentages $-79.1 \%$ of FMs, $76.6 \%$ of CPs and $59.2 \%$ of GAs-responded that GTPTs were too costly. 
Fig. 1 Perception of benefits and concerns about GTPTs. A fivepoint Likert scale was used to measure the respondents' perception of benefits (a) and concerns (b) about GTPTs

\section{a}

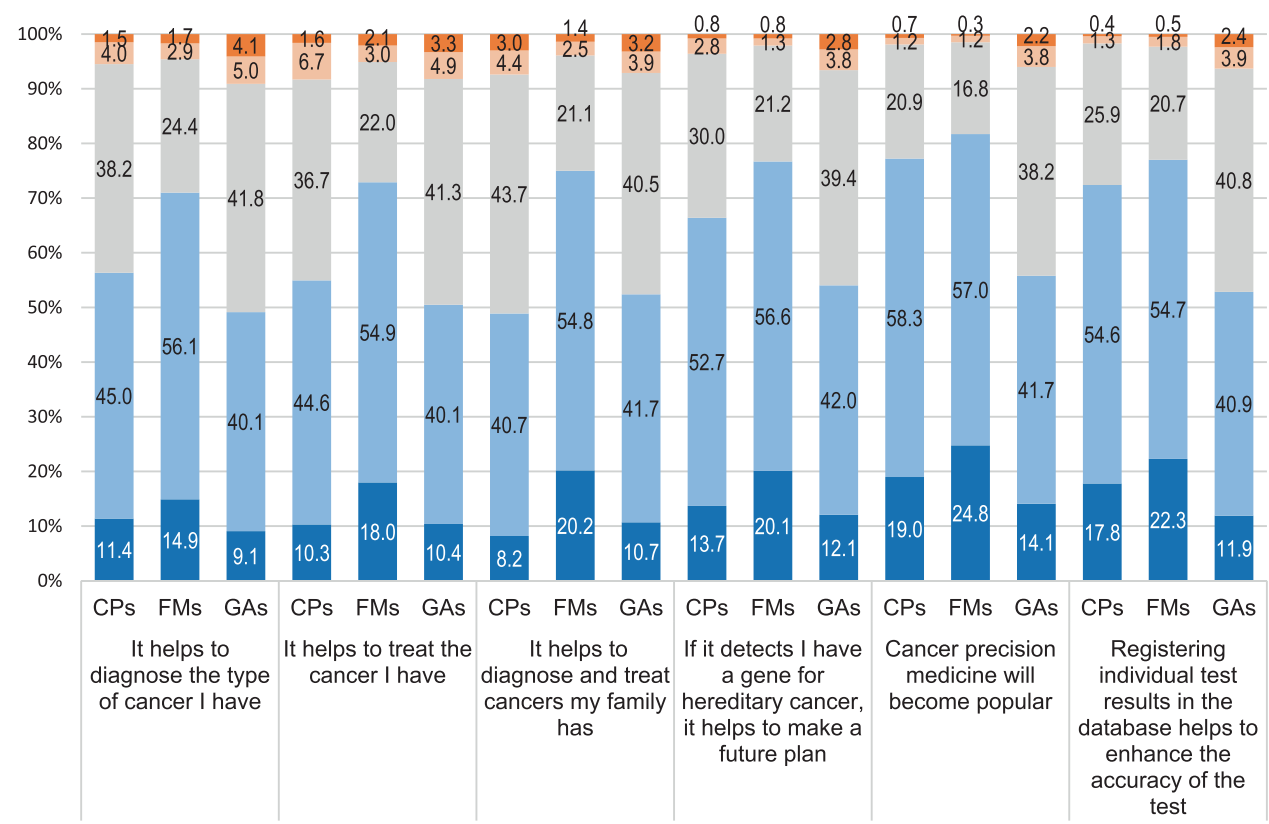

b

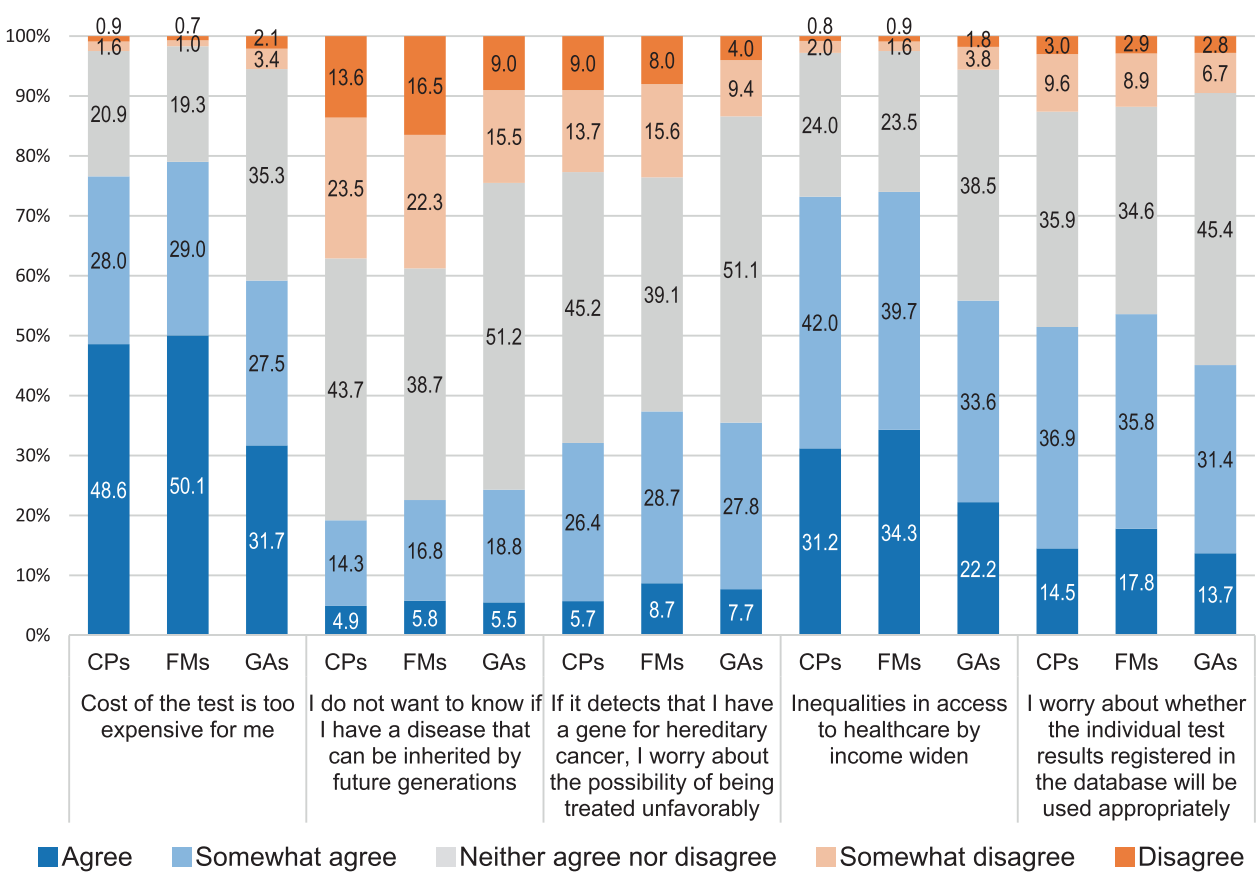

Although $77.0 \%$ of FMs and $72.4 \%$ of CPs felt that the submissions of individual test results to public databases would help enhance the accuracy of the tests, $53.6 \%$ of FMs and $51.4 \%$ of CPs worried about whether this data would be used appropriately.

About $20 \%$ of respondents in each group ( $\mathrm{FMs}=22.6 \%$, CPs $=19.3 \%$, and GAs $=24.3 \%$ ) did not wish to know whether they had a hereditary disease. More than $30 \%$ of them $(\mathrm{FMs}=37.4 \%, \quad \mathrm{CPs}=32.1 \%, \quad$ and $\mathrm{GAs}=35.5 \%)$ worried about the possibility of being discriminated against due to their genetic conditions.

Sixty-eight percent of CPs and $82.2 \%$ of FMs were willing to share information on germline findings, regardless of the results (Fig. 2). Due to concerns about causing anxiety and stress among family members, $3.8 \%$ of CPs preferred not to share. Only $1.8 \%$ of FMs agreed this idea, with the most common reason being, "It is better for me not to know." 
Fig. 2 Preferences for sharing information on hereditary cancer risk

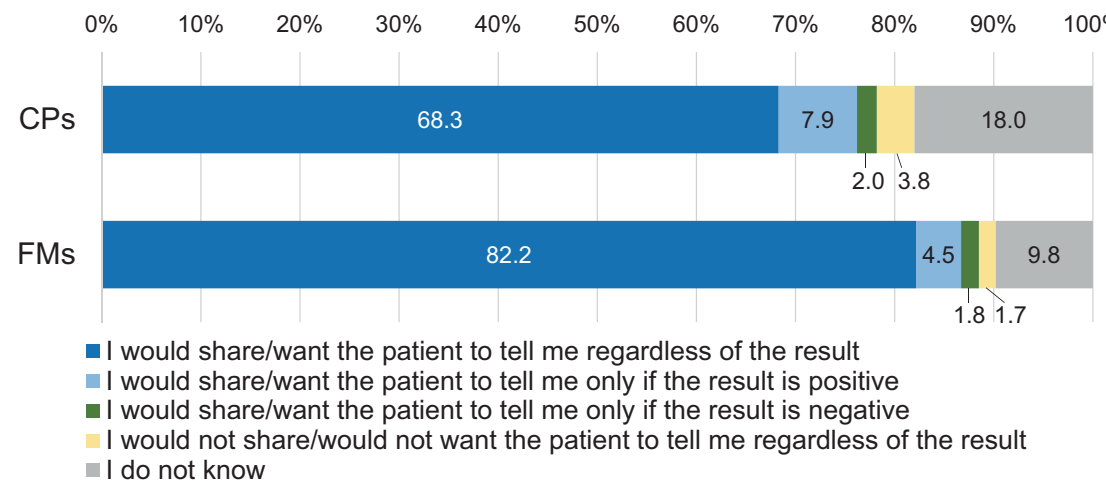

In Japan, the Ministry of Health, Labour and Welfare (MHLW) in 2018 designated 146 hospitals to provide GTPTs in close cooperation with each other and established the Center for Cancer Genomics and Advanced Therapeutics (C-CAT) as a public database to collect test results and related data. The MHLW also plans to cover GTPTs through National Health Insurance (NHI) for cancer patients with no further standard therapy options starting in 2019. Our survey was conducted before the MHLW's announcement about NHI coverage, so we need to carefully observe whether people's concerns about costs have changed. The main limitation of our study was that we could not include patients with advanced cancer who failed standard treatment and may be the main users of GTPTs in Japan. Nonetheless, we did find potentially meaningful commonalities in attitudes among patients, their family members, and the public, as well as interesting differences. First, both CPs and FMs showed a higher recognition of the benefits of GTPTs than GAs, confirming the results of previous studies. However, CPs and FMs might overestimate the probabilities of encountering the matched therapies derived from GTPTs. Second, despite the low possibilities to be revealed, FMs wanted information on germline findings to be shared more than CPs did. Patients must decide which of their family members they will share the germline findings, which may represent a heavy psychological burden. GTPTs should be offered along with advanced care planning for patients and genetic counseling options for family members who are interested in germline findings. Third, most of CPs and FMs had positive attitudes toward registering their data in the database, despite certain concerns about appropriate use. The C-CAT should disclose its data access policy for good governance and build up public trust.

Our study suggests that it is an urgent issue to inform cancer patients and the public about both the benefits and limitations of GTPTs. NHI coverage for GTPTs would have greater influence on the public perception of GTPTs. Therefore, it is important to continuously investigate their attitudes toward GTPTs.
Acknowledgements We express our gratitude to all the survey participants. This research was supported by AMED under grant number JP18cm0106001, and JSPS KAKENHI Grant Number JP15H05913, JP18K09940.

\section{Compliance with ethical standards}

Conflict of interest The authors declare that they have no conflict of interest.

Publisher's note: Springer Nature remains neutral with regard to jurisdictional claims in published maps and institutional affiliations.

Open Access This article is licensed under a Creative Commons Attribution 4.0 International License, which permits use, sharing, adaptation, distribution and reproduction in any medium or format, as long as you give appropriate credit to the original author(s) and the source, provide a link to the Creative Commons license, and indicate if changes were made. The images or other third party material in this article are included in the article's Creative Commons license, unless indicated otherwise in a credit line to the material. If material is not included in the article's Creative Commons license and your intended use is not permitted by statutory regulation or exceeds the permitted use, you will need to obtain permission directly from the copyright holder. To view a copy of this license, visit http://creativecommons. org/licenses/by/4.0/.

\section{References}

1. Robson ME, Bradbury AR, Arun B, Domchek SM, Ford JM, Hampel HL, et al. American Society of Clinical Oncology Policy Statement Update: genetic and genomic testing for cancer susceptibility. J Clin Oncol. 2015;33:3660-7.

2. Zehir A, Benayed R, Shah RH, Syed A, Middha S, Kim HR, et al. Mutational landscape of metastatic cancer revealed from prospective clinical sequencing of 10,000 patients. Nat Med. 2017;23:703-13.

3. Presley CJ, Tang D, Soulos PR, Chiang AC, Longtine JA, Adelson KB, et al. Association of broad-based genomic sequencing with survival among patients with advanced non-small cell lung cancer in the community oncology setting. J Am Med Assoc. 2018;320:469-77.

4. Hilal T, Nakazawa M, Hodskins J, Villano JL, Mathew A, Goel $\mathrm{G}$, et al. Comprehensive genomic profiling in routine clinical practice leads to a low rate of benefit from genotype-directed therapy. BMC Cancer. 2017;17:602. 
5. Kalia SS, Adelman K, Bale SJ, Chung WK, Eng C, Evans JP, et al. Recommendations for reporting of secondary findings in clinical exome and genome sequencing, 2016 update (ACMG SF v2.0): a policy statement of the American College of Medical Genetics and Genomics. Genet Med. 2017;19:249-55.

6. Johnson KJ, Gehlert S. Return of results from genomic sequencing: a policy discussion of secondary findings for cancer predisposition. J Cancer Policy. 2014;2:75-80.

7. May T. On the justifiability of ACMG recommendations for reporting of incidental findings in clinical exome and genome sequencing. J Law Med Ethics. 2015;43:134-42.

8. Vears DF, Niemiec E, Howard HC, Borry P. How do consent forms for diagnostic high-throughput sequencing address unsolicited and secondary findings? A content analysis. Clin Genet. 2018;94:321-9.

9. Liang R, Meiser B, Smith S, Kasparian NA, Lewis CR, Chin M, et al. Advanced cancer patients' attitudes towards, and experiences with, screening for somatic mutations in tumours: a qualitative study. Eur J Cancer Care. 2017;26:e12600.

10. Hamilton JG, Shuk E, Genoff MC, Rodriguez VM, Hay JL, Offit $\mathrm{K}$, et al. Interest and attitudes of patients with advanced cancer with regard to secondary germline findings from tumor genomic profiling. J Oncol Pract. 2017;13:E590-601.

11. Bylstra Y, Lysaght T, Thrivikraman J, Watson S, Tan P. Ethical frameworks for obtaining informed consent in tumour profiling: an evidence-based case for Singapore. Hum Genom. 2017;11:31.

12. Gray SW, Hicks-Courant K, Lathan CS, Garraway L, Park ER, Weeks JC. Attitudes of patients with cancer about personalized medicine and somatic genetic testing. JOP. 2012;8: 329-35.

13. Yushak ML, Han G, Bouberhan S, Epstein L, DiGiovanna MP, Mougalian SS, et al. Patient preferences regarding incidental genomic findings discovered during tumor profiling. Cancer. 2016;122:1588-97. 